\title{
Challenges Faced by Households in Caring for Orphans and Vulnerable Children
}

South Africa has seen a rapid increase in HIV prevalence among the general population over the past 10 years, from less than one percent in 1990 to twenty percent in 2001 (UNDP 2002). As the HIV/ AID S epidemic increases, so do the number of orphans and vulnerable children (OVC). In 2002, an estimated five million people (approximately 12 percent of the population) were living with HIV/ AIDS (Steinberg et al. 2002). Because of the average 10-year period between infection and death, even if HIV prevalence declined rapidly, South Africa would still experience an increasing orphan burden for many years to come. Projections show that by 2010, 16 percent of all children in South Africa, will be orphans and more than 70 percent will be due to AIDS (D ennis, Ross, and Smith 2002).

The N elson M andela Children's Fund (N M CF) seeks comprehensive local solutions to address the negative effects of H IV/ AIDS on children, adolescents, households, and communities. To this end, N M CF initiated the Goelama Project, ${ }^{1}$ which uses a community mobilization strategy to catalyze action by local organizations and government bodies to prevent HIV infection and mitigate the socioeconomic impacts of the disease, particularly as they affect OVC. N M CF recognizes that in order to develop indigenous responses to the epidemic, it is important to conduct research to delineate the problem, identify opportunities for intervention, and measure the effectiveness of interventions prior to replication or scale-up. This summary highlights key findings from a study of over 29,000 members of nearly 5,000 households in eight study sites to identify ways that government and communities can strengthen the socioeconomic capacity of households to care for and support OVC. The research was commissioned by N M CF and conducted by Development Research Africa (DRA), with technical assistance from the $\mathrm{H}$ orizons and FRON TIERS programs. The eight predominantly rural study sites were situated in the provinces of M pumalanga, Limpopo and KwaZulu $\mathrm{N}$ atal.

\section{Data Collection and Survey Sample}

Between D ecember 2001 and M arch 2002, researchers conducted a household survey using a cluster random sample research design. Respondents lived in eight districts, each of which is a local government demarcation unit under the jurisdiction of the $D$ istrict Council. The study sites and corresponding districts are Ehlanzeni in M pumalanga Province; M opani, Vhembe, and Capricorn in Northern Province; and U mkhanyakude, $\mathrm{M}$ pukonyoni, $\mathrm{U}$ thungulu and $\mathrm{UM}$ lalazi, $\mathrm{M}$ thonjaneni and $\mathrm{N}$ kandla municipalities in KwaZulu-N atal.

In each household one respondent, the household head, was selected to be interviewed. In the temporary absence of the head of the household, the person responsible for the daily decision-making, buying of food, or taking care of the children was interviewed. The final sample of 4,966 respondents included designated household heads ( 72 percent), spouses or

\section{Horizons}

FRONTIERS

IN REPRODUCTIVE HEALTH

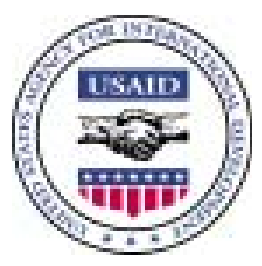


permanent partners ( 23 percent) and children or stepchildren ( 3 percent) of the household head, and other relatives ( 2 percent). These respondents provided information on 29,338 household members (approximately 6 members per household), and included nearly 14,000 children. D ata show that 52 percent of the household heads were male. $\mathrm{H}$ ousehold heads ranged in age from 14 to 106 years with a mean age of 51 years.

\section{Key Findings}

$\mathbf{N}$ early one in five children in the study population are orphans. Children have multiple needsphysical, material, intellectual, psychosocial, and safety-and it is important to identify groups of children whose social circumstances may affect the extent to which these needs are met. Respondents provided information on the orphanhood status of children aged 18 years or younger living in the household. Five percent of children had lost their mother and more than three times as many (16 percent) had lost their father. Two percent had lost both parents. As indicated in Figure 1, nineteen percent of all children were maternal, paternal, or double orphans and live in more than a quarter of study households. Living arrangement patterns among orphans show that 39 percent lived with the grandparent(s) and sixteen percent lived with a parent in the grandparent's house.

In addition to orphanhood, parental illness is a significant reality in G oelama areas; 13 percent of households had at least one child whose parents experienced a serious illness in the past 12 months. 0 verall 11 percent of children in the sample had a mother, father, or both parents who had been seriously ill during the 12-month period (see Figure 1). M ore children had sick mothers ( 8 percent) compared to sick fathers ( 6 percent). 0 nly one percent of children had both parents experiencing serious illness.

Figure 1 also indicates that one or both parents did not live with more than half ( 52 percent) of the children in the study sample. Children were more likely not to live with their fathers ( 54 percent) than with their mothers (19 percent). Thirty-nine percent of children did not live with at least one natural parent and 13 percent did not live with both natural parents.

Figure 1 Vulnerability of children

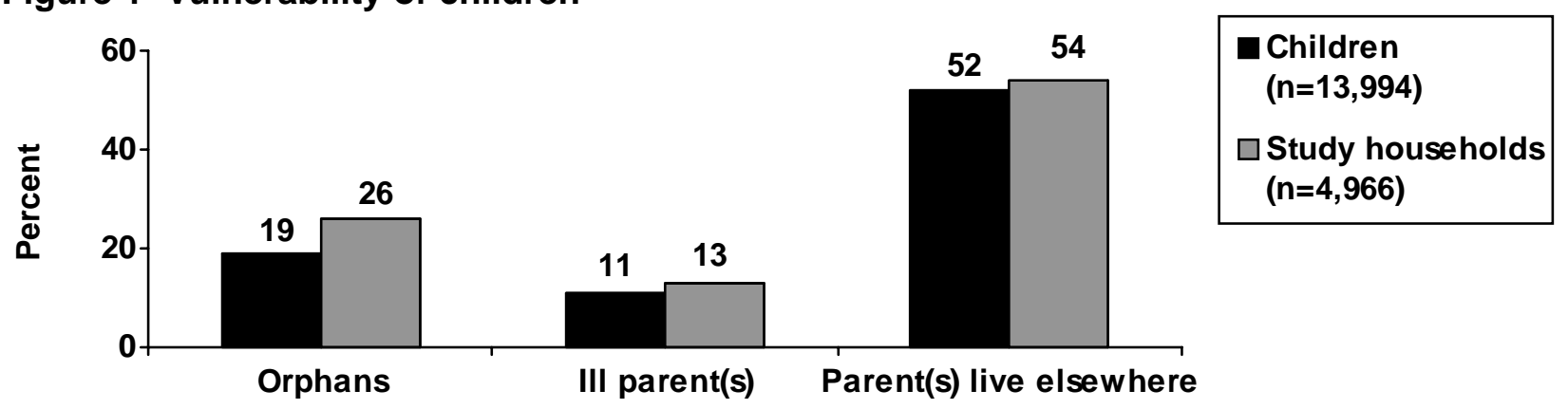

O rphanhood and parental illness affect school enrollment and attendance. Seven percent of children in the study households, aged 7-18 years, were not enrolled in school, mainly due to financial difficulties (50 percent), disability (14 percent), personal illness (10 percent) and pregnancy ( 8 percent). O rphans were more likely to have dropped out of school compared to non-orphans ( 9 vs. 6 percent, $p<.001$ ) with financial difficulties as the main reason. Children with seriously ill parents were more likely to have dropped out of school ( 8 percent) compared to children with healthy parents ( 6 percent). Similarly, children affected by parental illness were more likely to have stopped attending school because of care giving (5 percent), poor behavior (14 percent) and poor school performance (12 percent) compared to children whose parents were healthy ( 3,4 and 7 percent, respectively). Cross tabulations of education by age shows that many children are lagging behind their education cohort, suggesting either late onset of education or high failure rates. 
M any children are not fully immunized. Almost all children aged six years or younger (97 percent) living in the household had immunization cards (known as the 'road to health' cards) yet only 63 percent had received measles and DPT 3 injections. Children affected by serious parental illness were less likely to receive both measles and DPT injections ( 59 percent) compared to those whose parents were healthy (64 percent). The study findings also indicate that in only 17 percent of households, respondents noted that the youngest child (aged 18 years or younger) had eaten food from three food groups-starches, fruits and vegetables, and proteins-in the week prior to the study. Respondents from households that had experienced parental illness during the twelve months preceding the survey were more likely to report that the youngest child (aged 18 years or younger) was fed food from all three food groups in the week prior to the study compared to households that did not have children with seriously ill parents ( 19 vs. 17 percent; $p<.01$ ). There were no statistically significant differences in the consumption of foods from the three food groups by orphaned children compared to non-orphans as reported by study respondents.

\section{Female-headed households are more likely to be poor and include orphans than male-headed} households. About half of the households surveyed (48 percent) were headed by females. The data indicate that female-headed households were significantly more likely to report that they earned monthly income that is at or below the poverty line ${ }^{2}$ compared to male-headed households (74 vs. 61 percent; $p<.001$ ). The study findings also show that female-headed households were more likely to have a parent living away from home (62 percent) compared to male-headed households ( 38 percent). This is largely due to higher migration rates among males compared to females. Sixty eight percent of female-headed households included children who were orphaned compared to 32 percent of male-headed households $(p<.001)$.

A substantial number of household heads are elderly and have had no schooling. The households in Goelama sites showed strong family cohesiveness. O $\mathrm{n}$ average, over two-thirds (68 percent) of household members were immediately related and almost a third (30 percent) had an extended family relationship with the household head. Thirty-eight percent of children lived with one or more grandparents. O nly two percent of children lived with non-relatives.

When examining household headship, the study found that 21 percent of household heads were 65 years or older (Figure 2). At the opposite end of the age spectrum, 2 percent of study households were headed by youth aged 14-24 years.

Figure 2 Age profile of household heads

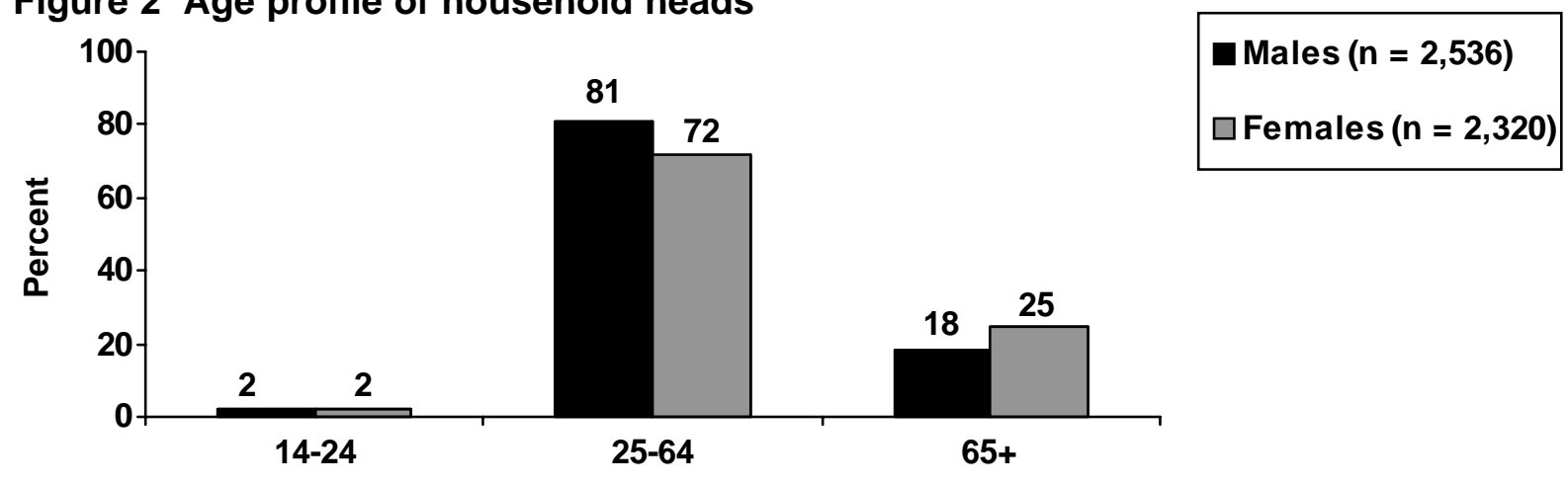


About a third ( 35 percent) of household heads had no schooling and enrollment in adult education programs was very low ( 0.1 percent). As Figure 3 indicates, almost half of household heads ( 44 percent) in the study were gainfully employed and 24 percent said they were unemployed. Consistent with the finding that a large proportion of elderly were heading households, 26 percent of household heads were retired.

\section{Figure 3 Occupation of household head}

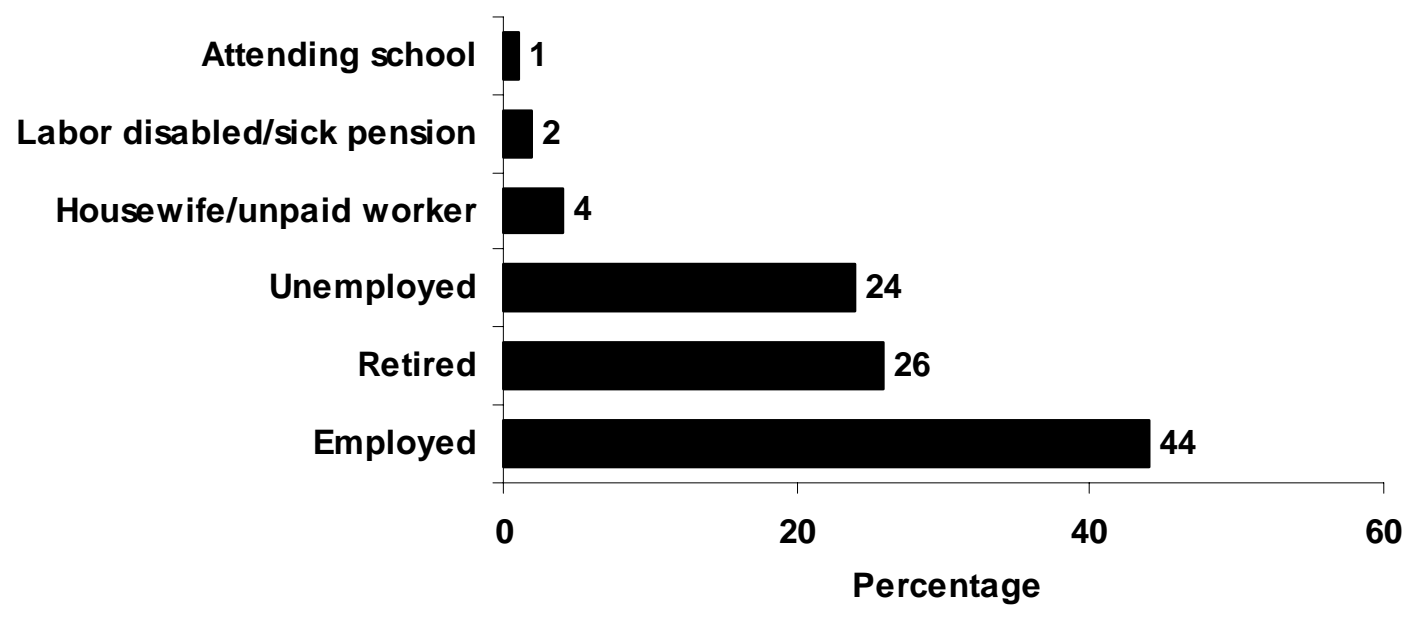

The majority of households earn monthly income that is at or below the poverty line. The findings reveal that the socioeconomic status of households is generally low, which may be partly due to the rural selectivity of the sample- 76 percent of the sampled households were in rural areas. Two-thirds of households reported an average monthly income of R800 or less. The proportion of households who worked and earned income is also low; only 34 percent of households reported that they received income from full time employment, 13 percent from part-time, and 8 percent from casual employment. D espite the low contribution of employment to household income, reported involvement in income generating activities was also low-just 16 percent of households receive income from self-employment.

Government grants make a significant contribution to household income. $\mathrm{n}$ average, income from government grants contributes to more than half of total household income. As shown in Table 1, grants contribute a mean proportion of 53 percent and a median proportion of 83 percent of household income per month for the 3,758 respondents that provided information on household income. Existing access ${ }^{3}$ and new applications $\mathrm{s}^{4}$ to grants are presented in Table 1. A part from old age pension, reported access to other grants was low. Less than a third of eligible households reported that they were in receipt of child support, foster care, disability, and care dependency grants. The proportion of households with members who had submitted new applications was also low.

Table 1 Access to government grants

\begin{tabular}{lccc}
\hline Benefit & $\begin{array}{c}\text { Value/ } \\
\text { percentage per month }\end{array}$ & $\begin{array}{c}\text { Existing access among } \\
\text { eligible households }\end{array}$ & $\begin{array}{c}\text { New } \\
\text { applications }\end{array}$ \\
\hline Mean \% of grants to household income & $53 \%$ & NA & NA \\
Median \% of grants to household income & $83 \%$ & NA & NA \\
Child support grant $(n=3,174)$ & R160/US $\$ 22$ & $28 \%$ & $7 \%$ \\
Care dependency grant $(n=657)$ & R700/US $\$ 95$ & $5 \%$ & $2 \%$ \\
Old age pension $(n=1,630)$ & R700/US $\$ 95$ & $83 \%$ & $5 \%$ \\
Disability grant $(n=711)$ & R700/US $\$ 95$ & $32 \%$ & $3 \%$
\end{tabular}

The "n"s refer to the number of eligible households for each grant. $\mathrm{NA}=$ not applicable 
H ouseholds experience events that can deepen existing poverty. The study findings highlight the extent to which households experience destabilizing events that can deepen poverty of already poor households. Commonly mentioned events that occurred during the two-year period prior to the survey were death (21 percent), serious illness or injury (15 percent), loss of regular income (10 percent), theft, fire or property grabbing ( 9 percent), and loss of crops and/ or livestock ( 5 percent). O ther events-cut-off of remittance, abandonment or divorce, cut-off of a government grant and business failure or bankruptcy were each mentioned by two percent or less of household respondents.

$\mathrm{H}$ ouseholds with children whose parents had fallen ill during the 12 months prior to the study were significantly more likely to earn income at or below the poverty line compared to households with healthy parents ( 74 vs. 66 percent; $p<.001$ ). A similar difference with regard to income status was found when comparing households with and without orphans -69 vs. 66 percent $(p<.05)$

Of all households that experienced death during the recall period, 12 percent lost two members and 5 percent lost three or more household members. Strategies taken to cope with death and serious illness included asset depletion (14 and 67 percent, respectively) and increased indebtedness ( 21 and 30 percent, respectively).

\section{$M$ any households are unable to plan for adverse and destabilizing events because of a lack of} assets. The study found that the majority of households ( 61 percent) did not own any financial assets. As indicated in Figure 4, approximately a quarter (26 percent) of households owned a savings account, but fewer households had invested in life insurance, medical insurance, and pension plans as well as stockvel ${ }^{5}$ savings.

Figure 4 Financial assets of households

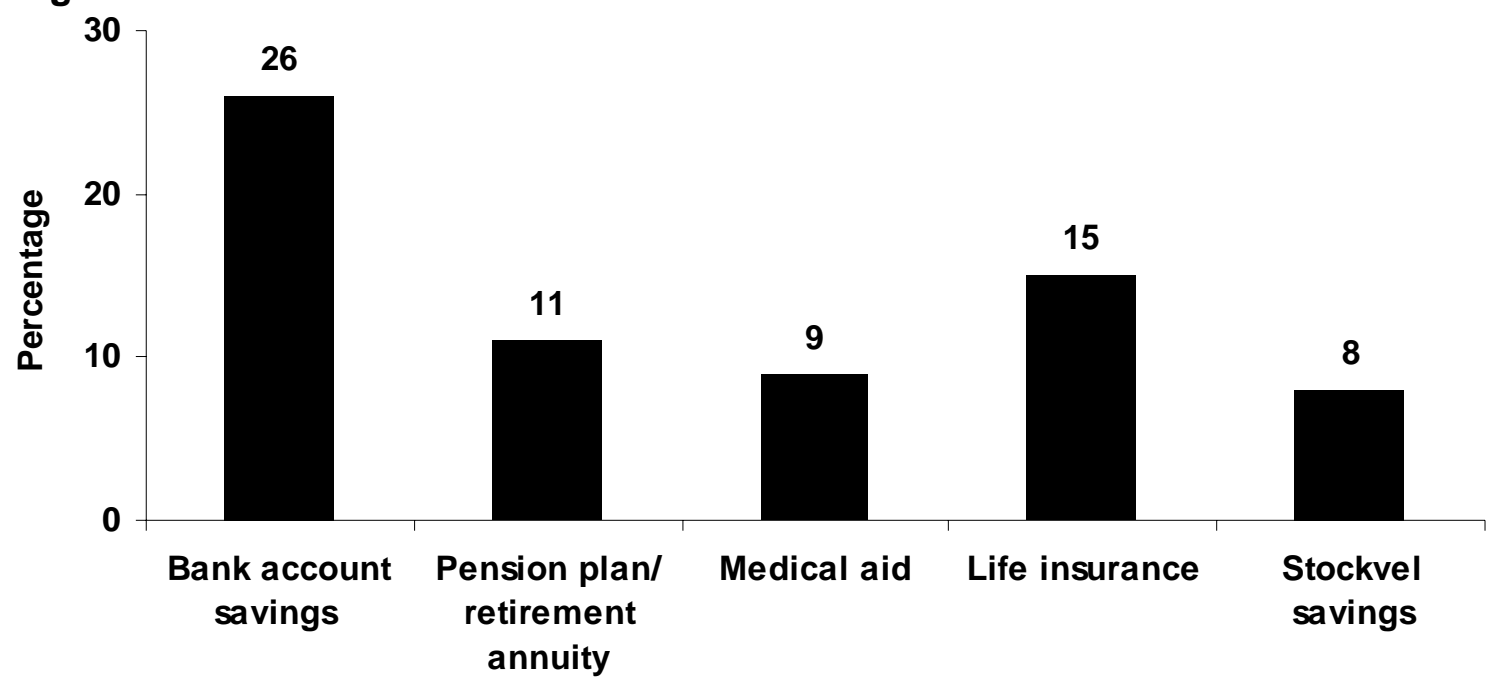

The legal preparedness of households is uneven, thereby affecting grant applications and inheritance rights. Figure 5 shows that registration of births and deaths was high. Birth registration is a prerequisite to attaining the national identity document, which, in turn facilitates applications for grants. D eath registration precedes inheritance and may be a barrier in fulfilling succession plans. But only 3 percent of respondents had a will and only 14 percent of households had a title deed to the house they were living in at the time of the survey. 


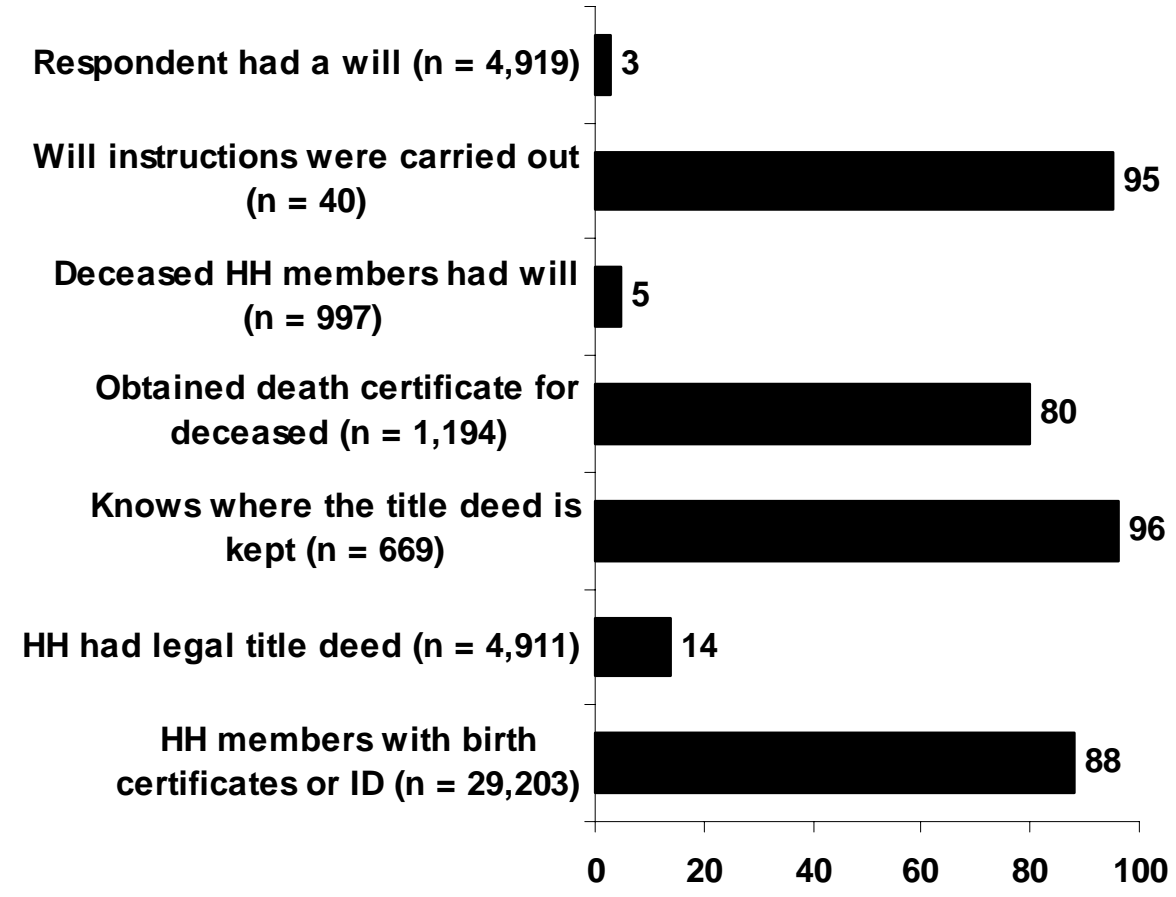

\section{A part from religious and burial groups, membership in community groups is low.}

The study found that apart from membership in religious groups ( 79 percent) and burial societies (37 percent), household respondents' affiliation with community groups was low. When asked about participation in the last month, the reported frequency of participation in group activities was low for religious and burial groups. H owever, as indicated in Table 2, groups that did not have many members in the community, such as sports, music and dance groups had the advantage of engaging members in more meetings (6-8 times) per month.

Table 2 Participation in community groups by household respondents $(n,=4,966)$

\begin{tabular}{lcc}
\hline Community group & $\begin{array}{c}\text { Membership } \\
(\%)\end{array}$ & Participation per month \\
\hline Religious & 79 & 1 \\
Burial societies & 37 & 1 \\
Sports & 2 & 6 \\
Music and dance & $<2$ & 1 \\
Stockvels & 6 &
\end{tabular}

\section{M ost respondents have positive perceptions of community connectedness and help}

neighbors when needed. To measure social capital and community connectedness, respondents were asked if they agreed or disagreed with specific statements. Fifty-nine percent of respondents felt they had many friends in the neighborhood. A higher proportion of respondents (77 percent) felt that the children in the household had many friends in the community. For these two measures there were no significant differences between respondents living in households with orphans and those respondents living in households without orphans. M ore than four in five respondents felt most adults in the community would help the respondent's family when they were in trouble (87 percent). Although high, respondents from households with orphans were slightly less likely to agree with the statement compared to respondents belonging to households with no orphans (87 vs. 88 percent, respectively; $\mathrm{p}<.001$ ). M ost respondents felt that people in their neighborhood work together to deal with issues affecting them (84 percent) and 77 percent felt that people in the neighborhood trust one 
another. Generally, most respondents felt well rooted in their communities and only 11 percent reported that they would be much happier in another community.

To assess household respondent's participation in the provision of assistance to members of their community, respondents were asked to describe how often they provide assistance with various activities. M ore than half of respondents provide some support in caring for children (59 percent), supporting neighbors during funerals (95 percent), preparing or giving food to neighbors ( 70 percent), and helping neighbors when they are sick (73 percent). 0 ther activities included shopping for neighbors ( 51 percent) and lending money ( 52 percent) or food and goods to neighbors (58 percent). Fewer respondents were involved in making/ fixing things ( 40 percent) and doing unpaid housework (44 percent) for neighbors.

\section{Few household members participate in ongoing care and support for seriously ill community} members. Reported participation of household members in caring for and supporting seriously ill community members outside the household was low (13 percent). A significantly greater proportion of females provided care and support to the seriously ill compared to males (14 vs. 11 percent; $p<.001$ ). As shown in Figure 6 , the burden of care falls mostly on older adults aged 35 years and over. As the number of people who need care increase, more family members are compelled to render care and support services. As indicated in Figure 6, 20 percent of those who helped provide care outside of the immediate household were children and youth. Care and support occurs in a challenging community environment, where 19 percent of households do not have access to clean water and almost a quarter of households were without toilet facilities.

\section{Figure 6 Age distribution of household members providing care and support to seriously ill community members}

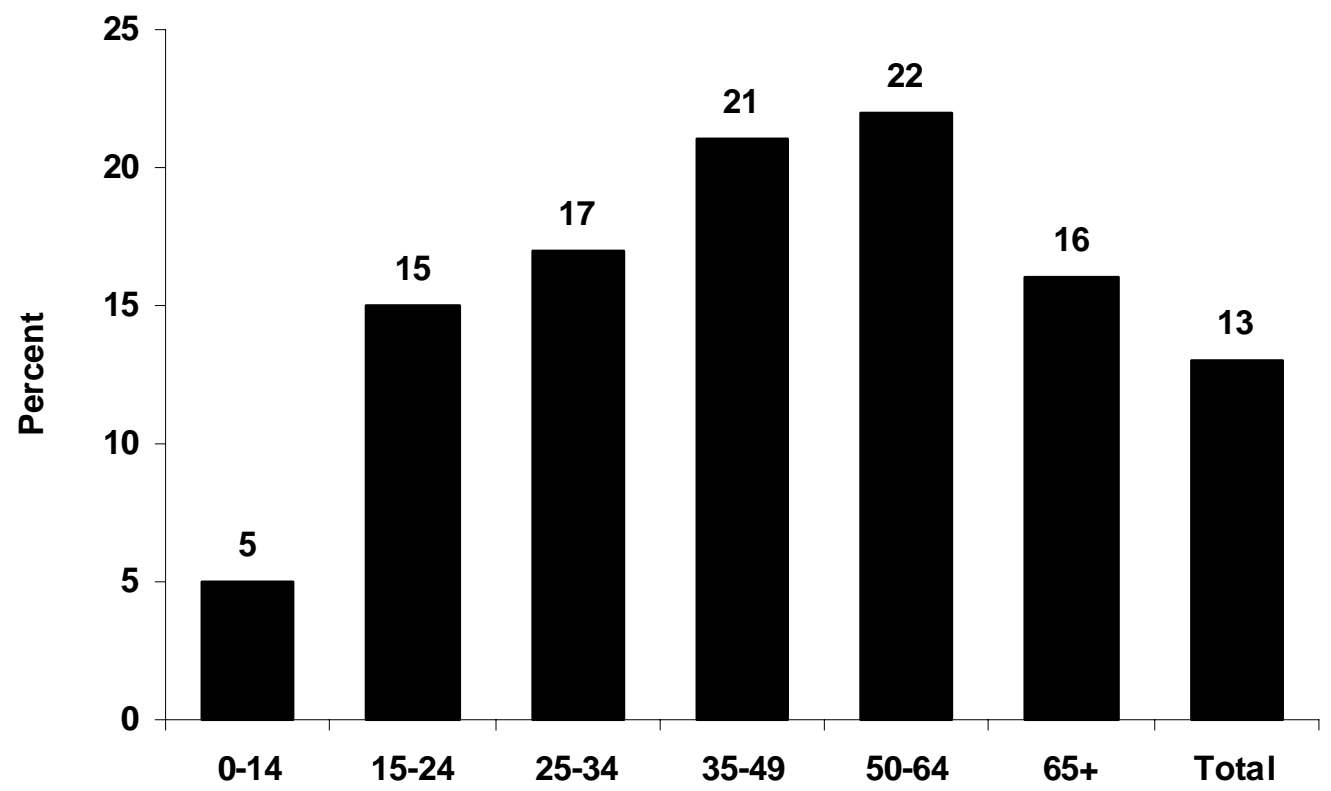

Age in years

\section{Conclusion}

The findings show that many households' capacity to support and care for OVC is precarious. The extent of poverty in the study area is widespread, and many factors increase households' economic vulnerability, including death, illness, a lack of assets, and households headed by women and elderly people. Extended family networks play an important role in the care of orphans and vulnerable children, but many of these families live in extreme poverty. Government grants make a major contribution to household income but many households are not accessing the government support benefits to which they are eligible. H ouseholds 
affected by serious illness, death, and orphanhood need help from external sources to ensure that the developmental needs of children are met and maintained. The study identified the following community needs and potential responses that could be undertaken by $\mathrm{NGO}$ s, community-based organizations ( $\mathrm{CBO}$ s), communities, and government structures.

i. L ow household income, savings and employment levels highlight a need for income generating activities and community based savings and livelihood solutions.

ii. CBOs can network with local government and put in place referral systems that facilitate application for government grants by needy households and efficient follow up to shorten the turnaround period.

iii. L ow levels of schooling among household heads should be given consideration in designing community programs and printing community education and awareness materials.

iv. There is a need for community outreach to encourage vaccinations and adherence to immunization regimens.

$v$. The potential for religious groups and burial societies to provide entry points for mobilizing community members to become involved in the care and support of OVC and seriously ill people should be examined.

vi. Gender issues should be integrated into interventions by encouraging male involvement in care and support, and family life. This would facilitate the construction of positive role models and encourage communities to promote more equitable gender norms.

January 2004

\footnotetext{
1 "G oelama" is a T swana term for nurturing and caring.

${ }^{2} \mathrm{H}$ ousehold poverty line is R $800 / \mathrm{U} S \$ 109$ per month.

${ }^{3}$ Existing access to grants refers to households with eligible members who were already receiving monthly grants at the time of the survey.

${ }^{4} \mathrm{~N}$ ew applications to grants refer to households with eligible members who reported that they had applied for a grant, but were not in receipt of monthly government transfers at the time of the survey.

${ }^{5}$ Refer to indigenous community savings and income generating schemes that were commonly utilized during the apartheid era for black economic empowerment.
}

\section{References}

U N D P. 2002. H uman D evelopment Report 2002: D eepening democracy in a fragmented world. N ew York: U nited N ations.

Steinberg, M . et al. 2002. H itting H ome: H ow households cope with the impact of the HIV/ AID S epidemic, a survey of households affected by HIV/ AID S in South A frica. Washington D C: H enry J. Kaiser Family Foundation and $\mathrm{H}$ ealth Systems T rust.

D ennis, M., J. Ross, and S. Smith (eds). 2002. Children on the brink 2002: A joint report on orphan estimates and program strategies. Washington DC: The Synergy Project.

\section{Hgrizons}

Horizons conducts global operations research to improve HIV/AIDS prevention, care, and support programs. Horizons is implemented by the Population Council in partnership with the International Center for Research on

Women (ICRW), the Program for Appropriate Technology in Health (PATH), the

International HIV/AIDS Alliance, Tulane

University, Family Health International (FHI), and Johns Hopkins University.

\section{FRONTIERS \\ IN REPRODUCTIVE HEALTH}

The Frontiers in Reproductive Health Program (FRONTIERS) applies systematic research techniques to improve delivery of family planning and reproductive health services and influence related policies. FRONTIERS is funded by the U.S. Agency for International Development (USAID) and led by the Population Council in collaboration with Family Health International and Tulane University.

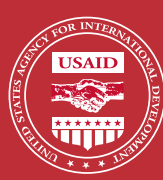

This publication was made possible through support provided by the Office of HIV/AIDS, Bureau for Global Health, U.S. Agency for International Development. The opinions expressed herein are those of the authors and do not necessarily reflect the views of the U.S. Agency for International Development.

For more information, contact:

Population Council/Horizons and Frontiers Communications Units

4301 Connecticut Ave, NW, Suite 280

Washington DC 20008

USA

Tel: $+202-237-9400$

Fax: +202-237-8410

Email: horizons@pcdc.org/frontiers@pcdc.org

http://www.popcouncil.org/horizons http://www.popcouncil.org/frontiers 